\title{
O USO DO JOGO PROTAGONIZADO NA EDUCAÇÃO INFANTIL
}

\author{
EL USO DEL JUEGO PROTAGONIZADO EN EDUCACIÓN INFANTIL
}

THE USE OF THE GAME STARRING IN THE CHILDREN'S EDUCATION

\author{
Geovana Maria da Silva BELING ${ }^{1}$ \\ Karla Rodrigues de Souza BARBOSA ${ }^{2}$ \\ Antonio Marcos Gomes da Costa GONÇALVES ${ }^{3}$ \\ Rebeca Pizza Pancotte DARIUS ${ }^{4}$
}

RESUMO: A teoria do jogo protagonizado é proposta por Elkonin (2009) e consiste em explicar a principal atividade realizada pela criança em idade pré-escolar: a representação dos papéis sociais que as crianças assumem enquanto brincam. Para Elkonin (2009), essas representações auxiliam a criança na incorporação das normas sociais, como também colabora para um efetivo desenvolvimento das funções psíquicas dos alunos. Essa teoria também traz a necessidade da intervenção do professor no processo de realização do jogo. Portanto, considerando a relevância dessa atividade no processo educativo de pré-escolares, o objetivo da pesquisa é verificar a percepção dos docentes quanto ao jogo protagonizado e a sua realização na prática pedagógica em turmas de Educação Infantil. A pesquisa foi de cunho quali-quantitativo, realizada por meio de um questionário semiestruturado contendo seis questões objetivas com espaço para argumentação.

PALAVRAS-CHAVE: Jogo protagonizado. Funções psicológicas superiores. Educação infantil. Prática docente.

RESUMEN: La teoría del juego protagonizada es propuesta por Elkonin (2009) y consiste en explicar la principal actividad realizada por el niño en edad preescolar: la representación de los roles sociales que los niños asumen mientras juegan. Para Elkonin (2009), esas representaciones auxilian al niño en la incorporación de las normas sociales, como también colabora para un efectivo desarrollo de las funciones psíquicas de los alumnos. Esta teoría también trae la necesidad de la intervención del profesor en el proceso de realización del juego. Por lo tanto, considerando la relevancia de esa actividad en el proceso educativo de preescolares, el objetivo de la investigación es verificar la percepción de los docentes en cuanto al juego protagonizado y su realización en la práctica pedagógica en grupos de educación

${ }^{1}$ Centro Universitário Adventista de São Paulo (UNASP), Engenheiro Coelho - SP - Brasil. Graduanda em Pedagogia. ORCID: <http://orcid.org/0000-0001-5552-5208>. E-mail: geovanasilva.edu@gmail.com.

${ }^{2}$ Centro Universitário Adventista de São Paulo (UNASP), Engenheiro Coelho - SP - Brasil. Graduanda em Pedagogia. ORCID: <http://orcid.org/0000-0002-4171-6879>. E-mail: karla.souzabarbosa96@ gmail.com.

${ }^{3}$ Centro Universitário Adventista de São Paulo (UNASP), Engenheiro Coelho - SP - Brasil. Graduando em Pedagogia e graduado em Teologia. ORCID: <http://orcid.org/0000-0002-0321-4587>. E-mail: toninho_amg@hotmail.com.

${ }^{4}$ Centro Universitário Adventista de São Paulo (UNASP), Engenheiro Coelho - SP - Brasil. Coordenadora e professora do Curso de Pedagogia do Centro Universitário Adventista de São Paulo. Doutoranda em Educação Escolar FCLar/Unesp. Mestre em Educação pela Universidade Estadual de Maringá (UEM). ORCID: <http://orcid.org/0000-0001-7652-5450>.E-mail: rebecapizz@gmail.com.

RPGE - Revista online de Política e Gestão Educacional, Araraquara, v. 22, n. 3, p. 1098-1112, set./dez., 2018. E-ISSN:1519-9029. 
infantil. La investigación fue de cuño cual-cuantitativo, realizada por medio de un cuestionario semiestructurado conteniendo seis cuestiones objetivas con espacio para argumentación.

PALABRAS CLAVE: Juego protagonizado. Funciones psicológicas superiores. Educación infantil. Práctica docente.

ABSTRACT: The theory of the game is proposed by Elkonin (2009) and consists of explaining the main activity performed by pre-school children: the representation of the social roles that children assume while playing. For Elkonin (2009), these representations help the child in incorporating social norms, but also collaborates for an effective development of students' psychic functions. This theory also brings the need for teacher intervention in the process of playing the game. Therefore, considering the relevance of this activity in the educational process of preschoolers, the objective of the research is to verify the teachers' perception of the protagonist game and its accomplishment in the pedagogical practice in children's education classes. The research was qualitative-quantitative, carried out through a semi-structured questionnaire containing six objective questions with space for argumentation.

KEYWORDS: Gameplay starring. Higher psychological functions. Child education. Teaching practice.

\section{Introdução}

Imaginemos um grupo de crianças brincando de 'estrada de ferro' após participar de uma visita a uma estação ferroviária. Antes do início da brincadeira, a responsável pelas crianças lhes esclarece alguns quesitos importantes para a realização do jogo: um pau de madeira que servirá como sinal ferroviário de partida para o trem, biscoitos de verdade para a cantina, um papel contendo o escrito 'vendas de passagens', gorro vermelho para o chefe da estação usar, etc.:

Bóris é um chefe da estação, põe o gorro vermelho e empunha o pau com o aro. Delimitou um canto e explica: - Isso aqui é a estação onde vive o chefe. - Anatóli, Luísa e Elena são os passageiros. Colocaram uma cadeira atrás da outra e sentaram-se. As meninas levam bonecas. São suas filhas. Leonid: Como vamos viajar sem maquinista? Eu serei o maquinista. - Senta-se na cadeira da frente e faz "sssss...". Gália é a dona da cantina; montou-a colocando uma barreira de cadeiras pequenas diante de uma mesa. Em cima da mesa tem uma caixa com pedacinhos de papel, que fazem de dinheiro. Ao lado, sobre o uma folha de papel, filas de biscoitos cortados em pedaços (para que haja mais). - Tenho uma cantina muito abastecida - diz ela [...] (ELKONIN, 2009, p. 27).

Em determinada época do desenvolvimento infantil, é comum observarmos crianças brincando, sozinhas ou em grupo, de motoristas, médicos, professores, pais/mães, entre outros. A criança em idade pré-escolar amplia suas relações sociais, modifica suas necessidades e inicia 
um desenvolvimento do jogo em que ela passa a representa papéis, pois sua ânsia é participar de forma ativa no mundo adulto, e é por meio dele que consegue apropriar e incorporar as funções sociais dos adultos (LEONTIEV, 2006). Atividades desse teor são denominadas por Elkonin (2009) de jogo protagonizado, caracterizado por ele e Leontiev (2006) como atividade principal das crianças com idades de quatro ou cinco anos.

Para Elkonin (2009), esta brincadeira é a que mais promove desenvolvimento psíquico nessa fase da vida. No decorrer desta atividade, a criança tem a oportunidade de incorporar as normas sociais e apropriar-se do autodomínio da conduta. Ambos podem e devem ser aprendidos na escola, que por sua vez, precisa realizar isso de forma planejada e intencional (DUARTE, 2016). Tendo como base as formulações feitas por Elkonin (2009), chegamos à seguinte questão: a prática do jogo protagonizado é uma realidade nas instituições de educação infantil pesquisadas? Como hipótese para o estudo, sugerimos que o momento de jogos e brincadeiras na educação infantil seja realizado, na maioria das vezes, de forma espontânea, sem uma intervenção sistemática do professor.

Dessa maneira, o objetivo do estudo foi investigar a presença do jogo protagonizado nas práticas pedagógicas de professores inseridos na educação infantil, dada a sua importância no desenvolvimento psíquico dos alunos. Para tal, verificamos a necessidade de: (a) desenvolver um estudo teórico sobre as contribuições de alguns autores que abordam a importância do uso dos jogos protagonizados e o desenvolvimento das funções psíquicas superiores na idade préescolar, como Elkonin (2009); (b) identificar o conhecimento dos professores acerca das brincadeiras na educação infantil e como eles percebem essa prática; (c) analisar se os saberes desses professores acerca do brincar na educação infantil condizem com a teoria do jogo de Elkonin.

Esta pesquisa justifica-se por contribuir para nossa prática educacional enquanto futuros professores, bem como por poder colaborar com a prática docente no cumprimento de sua função social. A partir dela, podemos ter maior compreensão de como o jogo protagonizado contribui para o desenvolvimento psíquico e do autodomínio da conduta. Para a realização da pesquisa, foi necessária a aplicação de um questionário para trinta professores que atuam na educação infantil em escolas públicas e particulares de três municípios do interior do estado de São Paulo.

$\mathrm{O}$ questionário ${ }^{5}$, intitulado "O uso do jogo protagonizado na prática pedagógica de professores da educação infantil”, foi elaborado contendo seis sentenças semiestruturadas em

${ }^{5}$ Por se tratar de uma pesquisa que envolve a participação de seres humanos, esta investigação foi submetida ao Comitê de Ética e por ele aprovado por meio da Plataforma Brasil, tornando-a apta para a aplicação. 
que os entrevistados precisaram assinalar, numa escala de 1 a 5 , o grau de discordância ou concordância em relação à afirmação descrita. Havia também linhas com espaço para um comentário das questões, caso achassem necessário.

A apreciação do instrumento respondido pelos docentes tomou como referência a obra de Bardin (2016) para análise de conteúdo. Utilizamos as fases que Bardin (2016) sistematiza em sua obra: (a) pré-análise: sistematização das ideias e organização dos dados brutos; (b) exploração do material: decodificação, classificação e categorização do material; e, por fim, (c) tratamento dos resultados: interpretações e atribuição de sentido.

\section{Considerações acerca do jogo protagonizado}

Segundo Elkonin (2009), não há uma delimitação nem uma explicação satisfatória das diferentes formas de jogo, mas sabemos que o jogo é "uma atividade em que se reconstroem as relações sociais" (p. 20). O autor afirma que "o jogo nasce do decorrer do desenvolvimento histórico da sociedade como resultado da mudança de lugar da criança no sistema de relações sociais" (p. 80). Segundo ele, não há um momento histórico exato para o surgimento do jogo, pois ele pode ter surgido de diferentes formas entre diversos povos e em tempos diferentes.

O jogo protagonizado é considerado por Leontiev (2006) e Elkonin (2009) como sendo a atividade principal de crianças pré-escolares. Para eles, cada estágio da infância corresponde a um tipo de atividade principal, cujo desenvolvimento condiciona as mudanças fundamentais nos processos psicológicos da criança e as características de sua personalidade em um determinado estágio de seu desenvolvimento. A atividade principal ou dominante se caracteriza por ser uma atividade:

[...] cuja forma surgem outros tipos de atividade e dentro da qual eles são diferenciados; [...] uma atividade na qual processos psíquicos particulares tomam forma ou são reorganizados, por exemplo, os processos infantis da imaginação ativa são inicialmente moldados no brinquedo e os processos de pensamento abstrato nos estudos; [...] a atividade principal é a atividade da qual dependem, de forma íntima, as principais mudanças psicológicas na personalidade infantil, observada em um certo período de desenvolvimento. É precisamente no brinquedo que a criança, no período pré-escolar, por exemplo, assimila as funções sociais das pessoas e os padrões apropriados de comportamento (LEONTIEV, 2006, p. 64).

Esse período do desenvolvimento da criança tem como foco principal as relações que os adultos estabelecem entre si, e é por meio dessa atividade as crianças representam as relações sociais das atividades dos adultos e delas se apropriam (LEONTIEV, 2006), aprendendo a subordinar seu comportamento às exigências do papel que representam. Assim, percebemos o 
singular impacto que a atividade humana e as relações sociais produzem no jogo, evidenciando que os temas dos jogos não partem unicamente da criança, pois possuem um fundo social, não podendo ser, portanto, um fenômeno biológico, conforme defendem algumas teorias biologizantes do desenvolvimento.

Conforme Mukhina (apud PASQUALINI 2010, p. 185), "as crianças refletem no jogo a realidade que as circunda, de modo que quanto mais ampla for a realidade que as crianças conhecem, tanto mais amplos e variados serão os argumentos de seus jogos". Podemos perceber que o caminho inverso também pode ser feito: quanto mais restrito for o contato da criança com a realidade social, mais pobres e monótonos serão os argumentos de seus jogos (PASQUALINI, 2010).

\section{A incorporação das normas de conduta sociais por meio do jogo protagonizado e o desenvolvimento das funções psíquicas superiores}

Elkonin (2009) afirma que o jogo protagonizado tem seu conteúdo centrado principalmente nas normas que as pessoas estabelecem ao se relacionarem. $\mathrm{O}$ autor menciona que "ao representar um papel, o modelo de conduta implícito neste papel, com o qual a criança compara e verifica a sua conduta, parece cumprir simultaneamente duas funções no jogo: interpretação do papel e verificação do seu comportamento" (ELKONIN, 2009, p. 420). No jogo, a criança passa de um mundo desenvolvido de forma suprema de atividade humana a um mundo desenvolvido por regras entre as relações pessoais. Essas normas, por meio do jogo, desenvolvem a moral da própria criança (ELKONIN, 2009).

Na idade pré-escolar, a criança começa a expressar o entendimento de que, ao interpretar um papel social, ela necessita se adequar às regras de moral e conduta do papel desempenhado. Compreende essas normas e protesta contra o colega caso ele não esteja cumprindo o papel adequadamente, dizendo, enquanto brinca: 'não é assim que o professor faz', por exemplo. Isso é um sinal de que:

[...] ela conhece as regras daquele papel, o que nos permite deduzir que o papel se destaca claramente do eu infantil. Uma implicação disso é que, no jogo protagonizado, a criança é consciente de que está representando um papel, e não é o papel (MARCOLINO et al., 2014, p. 100).

E dessa forma a criança se humaniza por meio do jogo e este se reveste de importância para formar uma coletividade infantil bem ajustada, para inculcar independência, para educar no amor ao trabalho, corrigir alguns desvios comportamentais, entre outros (ELKONIN, 2009). 
Elkonin (2009, p. 421) afirma que "todos esses efeitos educativos se baseiam na influência que o jogo exerce sobre o desenvolvimento psíquico da criança e sobre sua formação da personalidade".

Considerando o psiquismo humano como um legado social, colocamos em questão o seu desenvolvimento e sua possível relação com o jogo protagonizado. Fazemos essa associação porque o jogo protagonizado é a atividade principal da criança pré-escolar e é a atividade principal que promove o seu desenvolvimento. Para essa compreensão, faz-se necessário o esclarecimento de alguns conceitos, como a própria expressão função psicológica.

Segundo Vigotsky (2001), as funções psíquicas são processos mentais dos seres humanos. São organizadas em duas ordens: elementares e superiores. $\mathrm{O}$ autor esclarece que a expressão ‘função psíquica elementar' remete a funções que estão presentes em seres humanos e animais. São ações involuntárias, reações imediatas que sofrem controle do ambiente externo. São de caráter biológico e imediatista. Já as ‘funções psicológicas superiores’ estão presentes somente no homem e são caracterizadas pelas ações intencionais, ou seja, comportamento consciente do homem, de cunho metacognitivo - o indivíduo é capaz de pensar sobre o próprio pensamento e ter domínio de sua própria conduta.

Esse processo, de promoção das funções psíquicas elementares para as superiores são processos que advêm de experiências sociais. Martins (2013) considera que as funções psicológicas superiores são: sensação, percepção, atenção, memória, linguagem, pensamento, imaginação e emoção. Essas funções são as que fornecem para o ser humano a capacidade de entender o mundo objetivo. Podemos inferir algumas questões considerando o funcionamento psicológico e o trabalho realizado com o jogo protagonizado. Uma grande quantidade de atividades, “[...] e o jogo não é exceção, pode decompor-se numa soma de faculdades: percepção + memória + pensamento + imaginação" (ELKONIN, 2009, p. 23).

Ao realizar um jogo em que há a presença do protagonismo, a criança necessita efetuar a representatividade e a incorporação das normas de conduta que são essenciais para que ela desempenhe o papel social que será representado por si mesma no jogo - o papel de um médico, por exemplo. De imediato, e com certa clareza, podemos observar que no ato da realização do protagonismo há a utilização de uma função psíquica superior essencial para a ocorrência do jogo: a imaginação. Vale ressaltar aqui que para Elkonin (2009) essa imaginação não significa uma fuga da realidade, tampouco do seu mundo cotidiano. Essa atividade, vivenciada pela criança de forma intensa e ampla, só lhe é possível justamente por ter ela o conhecimento da realidade. 
Além da função psíquica imaginação, podemos verificar outras funções que podem ser desenvolvidas por meio do jogo protagonizado. Elkonin (2009) descreve uma atividade caracterizada como jogo protagonizado: “um grupo de crianças brinca de 'estrada de ferro' num quarto amplo, depois de ter conhecido uma estação ferroviária durante uma viagem ao campo" (p. 26)

Analisando essa brincadeira de protagonismo mencionada por Elkonin (2009), podemos considerar que o professor pode e deve lançar mão desse expediente para a promoção das funções psíquicas superiores supracitadas, uma vez que cabe a ele fazer inferências durante a realização do jogo, realizando, de maneira previamente organizada, perguntas que irão requerer das crianças determinada função psíquica. Assim, o professor tem a possibilidade de organizar situações para o desenvolvimento infantil a patamares mais elevados.

\section{Jogo protagonizado na prática pedagógica da educação infantil}

Francisco (2011, p. 27) afirma que o jogo protagonizado não surge espontaneamente, mas sim "com a mediação dos adultos, de forma a criar situações e estimular as crianças". O jogo só irá promover desenvolvimento psíquico significativo se houver a mediação do professor, para que a criança amplie suas experiências de mundo:

O desenvolvimento do conteúdo desse jogo de papel se relaciona diretamente com a ampliação e a sistematização de conhecimentos pela criança, cabe então à escola de Educação Infantil organizar e ampliar ao máximo esse contato da criança com a realidade social (PASQUALINI, 2010, p. 185).

Pasqualini (2010) segue afirmando que na educação infantil é preciso acabar “com a artificial dicotomia entre 'atividades dirigidas' (supostamente para ensinar) e 'atividades livres' (supostamente para brincar), ainda tão presente nas escolas de Educação Infantil”' (p. 185). De acordo com o RCNEI - Referenciais Curriculares Nacionais da Educação Infantil -, documento-base para o currículo das escolas de educação infantil, a instituição de educação infantil deve "oferecer às crianças condições para as aprendizagens que ocorrem nas brincadeiras e aquelas advindas de situações pedagógicas intencionais ou aprendizagens orientadas pelos adultos" (BRASIL, 1998, p. 23).

O professor é o responsável por organizar a base estrutural das brincadeiras na vida da criança "por meio da oferta de determinados objetos, fantasias, brinquedos ou jogos, da delimitação e arranjo dos espaços e do tempo para brincar" (BRASIL, 1998, p. 23). Para melhor compreensão da importância da intervenção educacional no jogo protagonizado, Elkonin 
(2009) cita um experimento feito por uma professora: uma visitação das crianças ao jardim zoológico, acompanhadas pela educadora, em que puderam ver diversos animais, do que eles se alimentavam, etc.

Ao retornarem para a sala de aula, a professora, confiante em que as crianças iriam brincar de jardim zoológico, levou para a classe brinquedos com figuras dos animais vistos durante a excursão. Porém, o jogo não rendeu. A educadora voltou com as crianças ao jardim zoológico, mas, desta vez, intervindo e voltando a atenção das crianças para outro foco:

[...] os visitantes e o pessoal que cuidava dos animais, concentrando-se no trabalho do bilheteiro, dos porteiros que fiscalizavam a entrada, dos varredores das alamedas e das jaulas, do pessoal da cozinha que preparava a comida para os animais e a repartia, do guia que dava explicações ao público, do veterinário e seus auxiliares de enfermaria. Fez com que as crianças se fixassem na solicitude do pessoal com os animais, na amabilidade e no respeito do público às normas de conduta com os animais, nas relações entre os trabalhadores do jardim zoológico (ELKONIN, 2009, p. 32).

Depois de realizarem a segunda visita, as crianças começaram a brincar por conta própria de jardim zoológico, pois, devido à atitude de intervenção da professora, as crianças passaram a protagonizar diferentes papéis sociais que observaram. Dessa forma, podemos verificar que o jogo protagonizado tem sua base nas relações estabelecidas entre as pessoas por meio de suas ações com os objetos. O foco não é a relação do homem com o objeto, mas sim a relação que os homens constroem entre si (ELKONIN, 2009).

O professor deve proporcionar situações para que as brincadeiras ocorram de maneira diversificada, possibilitando a elaboração, de forma pessoal e independente, de suas emoções, sentimentos, conhecimentos e regras sociais (BRASIL, 1998). O fortalecimento do jogo protagonizado como recurso pedagógico na pré-escola resulta não somente em um ambiente lúdico, mas nas intervenções sistemáticas do mediador adulto. "Essas intervenções são realizadas por meio da direção da atenção e da percepção dos alunos para os fenômenos vivenciados, pela estimulação da imaginação e pela ampliação do universo cultural a ser imitado" (OTTONI; SFORNI, 2011, p. 9).

\section{Metodologia e análise dos dados}

A pesquisa contemplou o método quali-quantitativo com dados empíricos, cujo objetivo foi analisar a utilização do jogo protagonizado na prática dos docentes da educação infantil. Participaram da pesquisa trinta professores de educação infantil em escolas públicas e privadas de três municípios do interior do estado de São Paulo. 
O instrumento utilizado foi um questionário semiestruturado composto por seis sentenças em que cada participante assinalou, em uma escala de 1 a 5, o grau de concordância disposto dentre as seguintes opções: 1 - discordo plenamente; 2 - discordo; 3 - não concordo nem discordo; 4 - concordo; e 5 - concordo plenamente. Também se comtemplou espaço para o comentário das questões, caso os participantes achassem necessário. Das respostas obtidas por meio das questões assinaladas pelos professores, fizemos o agrupamento em três categorias, conforme indica a legenda.

Gráfico 1 - Questionário “O uso do Jogo Protagonizado na prática pedagógica de professores da Educação Infantil"

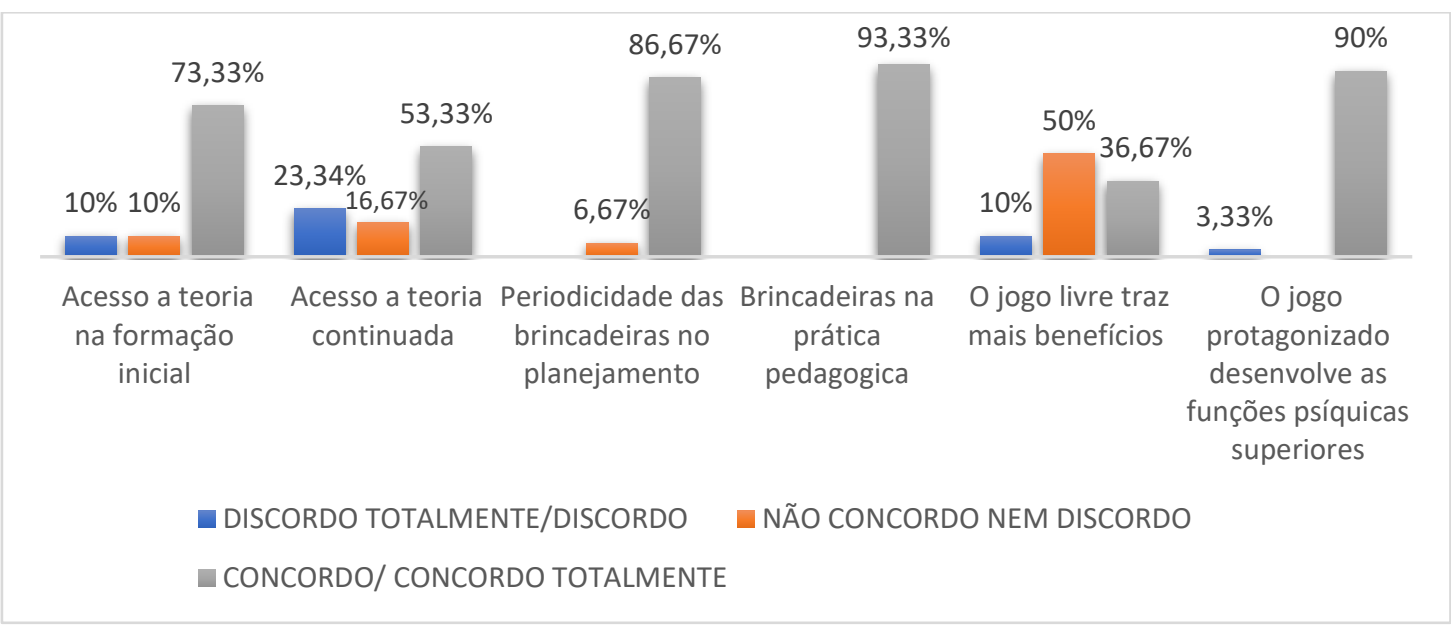

Fonte: Elaborado pelos autores

O primeiro e o segundo grupo de colunas do gráfico abordam o acesso que os professores tiveram sobre a teoria do jogo protagonizado e seus autores na graduação e na formação continuada. Destacamos que $73,33 \%$ e $53,33 \%$ afirmaram ter tido acesso à teoria e aos autores relacionados a ela. O terceiro e o quarto grupo de colunas se referem à frequência e à presença das brincadeiras no planejamento e na prática do professor. A maioria, $86,67 \% \mathrm{e}$ $93,33 \%$, afirmaram ter em seu planejamento e em sua prática a brincadeira. O penúltimo grupo de colunas faz referência ao jogo livre como sendo mais benéfico do que o jogo protagonizado. A maioria, 50\%, não toma um posicionamento específico. O último agrupamento alude ao jogo protagonizado como sendo promotor do desenvolvimento das funções psíquicas superiores, sendo que $90 \%$ concordam que há essa promoção por meio do jogo protagonizado.

Analisamos também os discursos contidos nas justificativas das questões. Por meio deles, atribuímos significado e descobrimos "núcleos de sentidos" (BARDIN, 2016, p. 135), discutindo-os à luz da teoria. Para a elaboração dos quadros, agrupamos os conteúdos das 
questões pela proximidade das temáticas, ficando da seguinte maneira: Quadro 1, temas centrais das questões 1 e 2; Quadro 2, temas centrais das questões 3 e 4; e Quadro 3, temas centrais das questões 5 e 6 . Dividimos os discursos contidos nas respostas dos professores em categorias e subcategorias de acordo com o disposto nos Quadros 1, 2 e 3.

Quadro 1 - Percepções dos professores acerca da Teoria do Jogo e dos autores Elkonin, Leontiev e Vigotsky na graduação e na formação continuada

\begin{tabular}{|c|c|c|c|}
\hline \multicolumn{2}{|c|}{$\begin{array}{l}\text { DISCURSOS CONTIDOS } \\
\text { NAS RESPOSTAS }\end{array}$} & \multicolumn{2}{|c|}{$\begin{array}{l}\text { RESULTADOS } \\
\text { QUANTITATIVOS }\end{array}$} \\
\hline CATEGORIAS & SUBCATEGORIAS & $\begin{array}{l}\text { NÚMERO DE } \\
\text { RESPOSTAS }\end{array}$ & $\begin{array}{c}\text { PERCENTUAL DE } \\
\text { RESPOSTAS } \\
\text { PARA } \\
\text { QUANTITATIVO } \\
\text { DE PERGUNTAS }\end{array}$ \\
\hline \multirow{4}{*}{$\begin{array}{l}\text { Oportunidade de acesso } \\
\text { à teoria e aos autores } \\
\text { estudados na graduação } \\
\text { e na formação } \\
\text { continuada }\end{array}$} & $\begin{array}{l}\text { Conhecimento parcial (um ou } \\
\text { dois autores ou somente a teoria) }\end{array}$ & 6 & $40 \%$ \\
\hline & $\begin{array}{l}\text { Conhecimento total (todos os } \\
\text { autores e a teoria) }\end{array}$ & 2 & $13,33 \%$ \\
\hline & $\begin{array}{l}\text { Associação da teoria ao lúdico } \\
\text { na Educação Infantil }\end{array}$ & 2 & $13,33 \%$ \\
\hline & $\begin{array}{l}\text { Sem conhecimento da teoria nem } \\
\text { dos autores }\end{array}$ & 5 & $33,33 \%$ \\
\hline TOTAL & & 15 & $100 \%$ \\
\hline
\end{tabular}

Fonte: Elaborado pelos autores

Ao analisar os comentários, encontramos quatro respostas discursivas diferentes, que foram divididas em subcategorias, em que $40 \%$ dos professores responderam que conheceram um ou dois dos autores mencionados - Vigotski, Leontiev e Elkonin - em algum momento de sua formação acadêmica, assim como podemos ver na resposta de um dos professores: 'Não, na minha formação tive a oportunidade de conhecer o autor Vigotsky, mas jogos na educação infantil e o lúdico que são brincadeiras, esses dois autores são novos'. Vemos que o professor confirma o conhecimento de um dos autores, mas não da teoria, não fazendo distinção entre o lúdico e o jogo protagonizado.

Somam um percentual de $13,33 \%$ os professores que responderam ter conhecimento dos autores e da teoria, e aqueles que afirmaram que não tiveram acesso nem aos autores nem à teoria do jogo protagonizado totalizam $33,33 \%$ das respostas. Ainda nesta mesma pergunta, tivemos $13,33 \%$ dos professores que associaram os autores mencionados à conhecimentos sobre a importância do lúdico na Educação Infantil. Um dos professores respondeu: 'Sim, essa 
atividade é fundamental na educação infantil, pois ela reconstrói as relações sociais e se apropria da experiência social da humanidade'.

Outras respostas não nos permitem um entendimento claro sobre o real conhecimento dos autores acerca da teoria, como essa: 'Sempre em todos os momentos aplicando atividades e em capacitações de professores sempre estamos estudando e aprendendo sobre a importância do lúdico dirigido ou não'. Em relação àqueles que não tiveram a oportunidade de conhecer os autores e/ou a teoria durante sua formação, destacamos a fala de um deles: 'Não foi explorado o tema na graduação'. Outro docente confirmou: 'Infelizmente não. São poucas escolas que se preocupam com a Ed. Infantil, embora seja base da educação básica, portanto não tive nenhum tipo de informação a respeito durante a formação continuada'. As falas demonstram que os professores gostariam de saber mais da teoria, uma vez que trabalham com Educação Infantil.

Quadro 2 - Percepção dos docentes quanto ao planejamento e quanto à prática do jogo protagonizado

\begin{tabular}{|c|c|c|c|}
\hline \multicolumn{2}{|c|}{$\begin{array}{l}\text { DISCURSOS CONTIDOS } \\
\text { NAS RESPOSTAS }\end{array}$} & \multicolumn{2}{|c|}{$\begin{array}{c}\text { RESULTADOS } \\
\text { QUANTITATIVOS }\end{array}$} \\
\hline CATEGORIAS & SUBCATEGORIAS & $\begin{array}{l}\text { NÚMERO DE } \\
\text { RESPOSTAS }\end{array}$ & $\begin{array}{c}\text { PERCENTUAL DE } \\
\text { RESPOSTAS PARA } \\
\text { QUANTITATIVO } \\
\text { DE PERGUNTAS }\end{array}$ \\
\hline $\begin{array}{l}\text { Periodicidade das } \\
\text { brincadeiras com } \\
\text { direcionamento/intervenção }\end{array}$ & $\begin{array}{l}\text { Realização de } \\
\text { brincadeiras } \\
\text { diariamente }\end{array}$ & 12 & $75 \%$ \\
\hline $\begin{array}{l}\text { Jogo protagonizado como } \\
\text { essencial para o } \\
\text { desenvolvimento da criança }\end{array}$ & -- & 4 & $25 \%$ \\
\hline TOTAL & & 16 & $100 \%$ \\
\hline
\end{tabular}

Fonte: Elaborado pelos autores

A primeira categoria do Quadro 2 faz referência à periodicidade que os professores disponibilizam para as brincadeiras com direcionamento em seu planejamento e prática. Do total, $75 \%$ realizam as brincadeiras diariamente. Um dos participantes relatou: 'Com certeza procuro incluir momentos de atividades lúdicas dirigidas e brincadeiras livres diariamente, porque acredito que a criança aprende brincando e isso faz parte da infância'.

É possível perceber também que há percepções diferentes a respeito do direcionamento e da intervenção aplicados nas brincadeiras: 'acredito que tem que haver brincadeira sem direcionamento (brincar livre) para o desenvolvimento da criança e tem que haver brincadeiras com direcionamento para que as crianças aprendam a ter regras, a dividir, compartilhar e criar' 
De acordo com Ottoni e Sforni (2011), as intervenções que o professor faz nas brincadeiras direcionadas são concretizadas por meio da direção, atenção e percepção dos alunos para os fenômenos vivenciados pela estimulação da imaginação e pela ampliação cultural a ser imitada. Os professores da educação infantil, conforme com o RCNEI, devem também "oferecer às crianças condições para as aprendizagens que ocorrem nas brincadeiras e aquelas advindas de situações pedagógicas intencionais ou aprendizagens orientadas pelos adultos" (BRASIL, 1998, p. 23).

Para 25\% dos participantes, o jogo protagonizado é essencial para o desenvolvimento das crianças. Percebemos isso nas seguintes falas: 'O brincar/jogo é essencial para o desenvolvimento integral das crianças, para que tenha seu desenvolvimento integral, e também amplie sua criatividade e expressão [...] ao reproduzir [...] a realidade por ela vivenciada'. Conforme já afirmamos, o jogo exerce grande importância para que haja o desenvolvimento psíquico da criança e a formação da personalidade (ELKONIN, 2009).

Quadro 3 - Percepções dos docentes acerca das brincadeiras livres e do jogo protagonizado para o desenvolvimento psíquico

\begin{tabular}{|c|c|c|c|}
\hline \multicolumn{2}{|c|}{$\begin{array}{l}\text { DISCURSOS CONTIDOS } \\
\text { NAS RESPOSTAS }\end{array}$} & \multicolumn{2}{|c|}{$\begin{array}{c}\text { RESULTADOS } \\
\text { QUANTITATIVOS }\end{array}$} \\
\hline CATEGORIAS & SUBCATEGORIAS & $\begin{array}{l}\text { NÚMERO DE } \\
\text { RESPOSTAS }\end{array}$ & $\begin{array}{c}\text { PERCENTUAL } \\
\text { DE RESPOSTAS } \\
\text { PARA } \\
\text { QUANTITATIVO } \\
\text { DE PERGUNTAS } \\
\end{array}$ \\
\hline \multirow{2}{*}{$\begin{array}{l}\text { O jogo livre traz mais } \\
\text { benefícios do que os } \\
\text { que têm intervenção } \\
\text { do professor }\end{array}$} & $\begin{array}{l}\text { Ambos trazem benefícios para } \\
\text { a criança }\end{array}$ & 10 & $71,43 \%$ \\
\hline & $\begin{array}{l}\text { O jogo sem o direcionamento } \\
\text { (jogo livre) do professor traz } \\
\text { mais benefícios }\end{array}$ & 1 & $7,14 \%$ \\
\hline $\begin{array}{l}\text { O jogo protagonizado } \\
\text { contribui para o } \\
\text { desenvolvimento das } \\
\text { funções psíquicas } \\
\text { superiores }\end{array}$ & - - & 3 & $21,43 \%$ \\
\hline TOTAL & & 14 & $100 \%$ \\
\hline
\end{tabular}

Fonte: Elaborado pelos autores

Conseguimos coletar dois tipos de respostas nessa temática, dividindo-as em subcategorias: primeira: $71,43 \%$ dos professores afirmaram que ambos os jogos trazem benefícios para o desenvolvimento dos alunos; segunda: 7,14\% acreditam que o jogo realizado de forma livre traz mais benefícios para desenvolvimento deles. Já na segunda questão, nossa intenção foi saber se os professores acreditavam que o jogo protagonizado pode promover o 
desenvolvimento das funções psíquicas superiores. Todos aqueles que responderam a essa questão concordaram com a afirmação de que ele pode desenvolver as funções psíquicas superiores. Um dos professores escreveu: ‘Sim, este momento é propício para liberar as funções psíquicas de um modo geral'.

Podemos perceber ainda que aqueles que indicaram o jogo livre como sendo importante também acreditam que o jogo protagonizado tem igual ou semelhante relevância para o desenvolvimento dos alunos nessa fase escolar. Isso nos revela que ou os professores não possuem clareza do que seja o jogo protagonizado e, portanto, de sua contribuição no processo do desenvolvimento psíquico, ou que, de fato, para eles existem momentos em que o jogo livre é necessário, e por isso tão importante quanto o jogo protagonizado. Destacamos a afirmação feita: ‘(...) o lúdico é muito importante para contribuir com o desenvolvimento da criança, tanto cognitivo, como físico e social'. Uma opinião compartilhada por todos que responderam ao questionário é a de que o lúdico é a melhor estratégia para o êxito do processo de ensino e aprendizagem.

\section{Considerações finais}

A realização do jogo protagonizado com crianças pré-escolas só tem a agregar no desenvolvimento psíquico delas. A necessidade das crianças consiste em reproduzir as funções e tarefas que os adultos exercem no seu dia a dia. É importante que os professores incluam em seu planejamento pedagógico momentos destinados à realização do jogo protagonizado com intuito de desenvolver as funções psicológicas superiores de seus alunos e o autodomínio da conduta.

A pesquisa empírica foi importante para a compreensão daquilo que os docentes pensam sobre o lúdico, o que conhecem e compreendem sobre o jogo protagonizado e, consequentemente, do que está sendo realizado na prática docente. Percebemos que a ocorrência de jogos e brincadeiras na educação infantil é constante, entretanto podemos verificar também que muitos desses docentes desconhecem a teoria do jogo protagonizado. Foi possível concluir que a realização de uma prática lúdica está associada ao fato de atuarem na educação infantil, em que os jogos e as brincadeiras são quesito necessário nessa fase escolar.

Por fim, e à luz dessas considerações, entendemos essa fase como sendo merecedora de uma atenção pedagógica que proporcione um desenvolvimento integral nas crianças, bem como a discussão da teoria e da prática no curso de formação de professores. Uma formação docente 
fundamentada na práxis transforma a educação, uma vez que proporciona aos docentes momentos de reflexão, criticidade e criatividade nas escolas.

\section{REFERÊNCIAS}

BARDIN, L. Análise de conteúdo. Tradução de Luís Antero Reto, Augusto Pinheiro. São Paulo: Edições 70, 2016.

BRASIL. Ministério da Educação. Secretaria de Educação Fundamental. Referencial curricular nacional para a educação infantil. Brasília: MEC/SEF, 1998.

DUARTE, N. Os conteúdos escolares e a ressurreição dos mortos: contribuição à teoria histórico-crítica do currículo. Campinas, SP: Autores Associados, 2016.

ELKONIN, D. B. Psicologia do jogo. Tradução de Álvaro Cabral. 2. ed. São Paulo: Editora WMF Martins Fontes, 2009.

FRANCISCO, L. S. O papel da atividade lúdica no desenvolvimento infantil:

contribuições de Elkonin. TCC - Trabalho de Conclusão de Curso, Curso de Pedagogia, Universidade Estadual de Maringá, Maringá, 2011. Disponível em:

http://www.dfe.uem.br/TCC/Trabalhos\%202011/Turma\%2032/Larissa_Francisco.pdf. Acesso em: 10 jan. 2018.

LEONTIEV, A. N. Uma Contribuição à Teoria do Desenvolvimento da Psique Infantil. In: VIGOTSKI, L. S.; LURIA, A. R; LEONTIEV, A. N. Linguagem, desenvolvimento e aprendizagem. 11. ed. São Paulo: Ícone, 2006, cap. 4, p. 59-83.

MARCOLINO, S.; BARROS, F. C. O. M.; MELLO, S. A. A teoria do jogo de Elkonin e a educação infantil. Revista Quadrimestral da Associação Brasileira de Psicologia Escolar e Educacional, SP, vol. 18, n. 1, 2014, p. 97-104. Disponível em: http://www.scielo.br/pdf/pee/v18n1/v18n1a10.pdf. Acesso em: 05 jun. 2018.

MARTINS, L. M. O desenvolvimento do psiquismo e a educação escolar: contribuições à luz da psicologia histórico-cultural e da pedagogia histórico-crítica. Campinas, SP: Autores Associados, 2013.

OTTONI, T. M. E; SFORNI, M. S. F. O brincar na educação infantil: explorando o jogo protagonizado. Congresso Nacional de Psicologia Escolar e Educacional, 2011, Maringá. Universidade Estadual de Maringá, 2011. Disponível em:

http://www.abrapee.psc.br/xconpe/trabalhos/1/157.pdf. Acesso em: 10 mar. 2018.

PASQUALINI, J. C. O papel do professor e do ensino na educação infantil: a perspectiva de Vigotski, Leontiev e Elkonin. In.: MARTINS, L. M; DUARTE, N. (orgs.) Formação de professores: limites contemporâneos e alternativas necessárias [online]. São Paulo: Editora Unesp; São Paulo: Cultura Acadêmica, 2010. Disponível em: http://books.scielo.org/id/ysnm8/pdf/martins-9788579831034-10.pdf. Acesso em: 10 mar. 2018. 
VIGOTSKY, L. S. Obras escogidas. Tomo II. Madrid: Visor, 2001.

\section{Como referenciar este artigo}

BELING, Geovana Maria da Silva.; BARBOSA, Karla Rodrigues de Souza.; GONÇALVES, Antonio Marcos Gomes da Costa.; DARIUS, Rebeca Pizza Pancotte O uso do jogo protagonizado na educação infantil. Revista on line de Política e Gestão Educacional, Araraquara, v. 22, n. 3, p. 1098-1112, set./dez., 2018. E-ISSN:1519-9029. DOI: 10.22633/rpge.v22i3.11511

Submetido em: 10/03/2018

Aprovado em: 30/07/2018 